\title{
VEGF autocrine secretion is enhanced by EGFR activation trough ERK1/2 phosphorylation in human Adrenocortical Carcinoma cell lines
}

\section{Teresa Gagliano ${ }^{1}$, Carmelina Di Pasquale ${ }^{1}$, Erica Gentilin ${ }^{1}$, Daniela Molè ${ }^{1}$,Martina Tassinari ${ }^{1}$, Mariaenrica Bellio ${ }^{1}$,}

Ettore degli Uberti ${ }^{1,2}$, Maria Chiara Zatelli ${ }^{1,2}$

${ }^{1}$ Section of Endocrinology, Department of Medical Sciences, University of Ferrara, Via Savonarola 9, 44121 Ferrara, Italy; ${ }^{2}$ Laboratorio in rete del Tecnopolo "Tecnologie delle terapie avanzate" (LTTA) of the University of Ferrara, Via Fossato di Mortara 70, 44121 Ferrara, Italy

\section{Background}

Adrenocortical cancer (ACC) is still orphan of medical treatment. ACC medical treatment is mainly represented by Mitotane alone or in association with chemotherapy, with variable results.

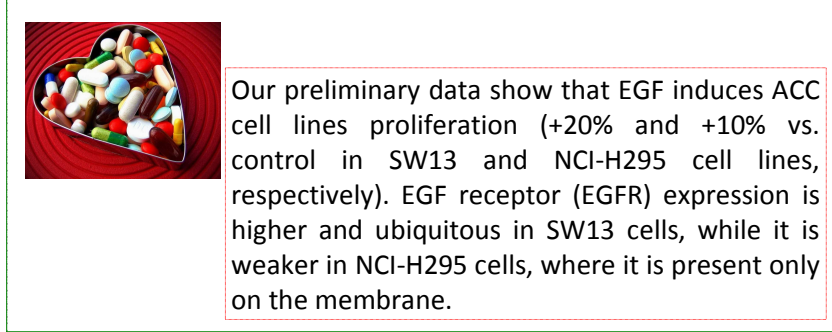

\section{Aim of our study is to analyze EGFR \\ downstream signalling in ACC cell lines \\ $\frac{1}{8}$}

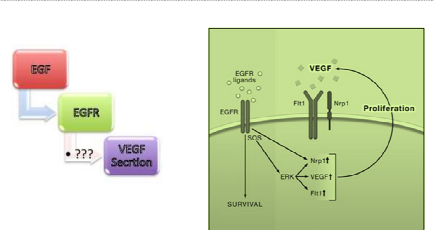

Compounds

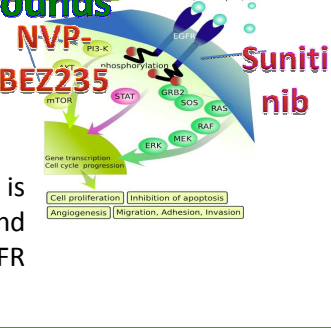

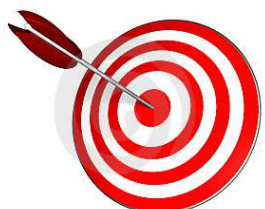

\section{RESULTS}

Evaluation of VEGF secretion
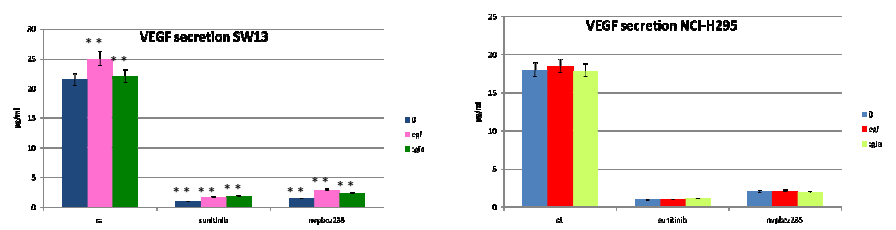

EGF and TGF-a enhanced VEGF secretion only in SW13 cells while had no effects on $\mathrm{NCl}-\mathrm{H} 295$.

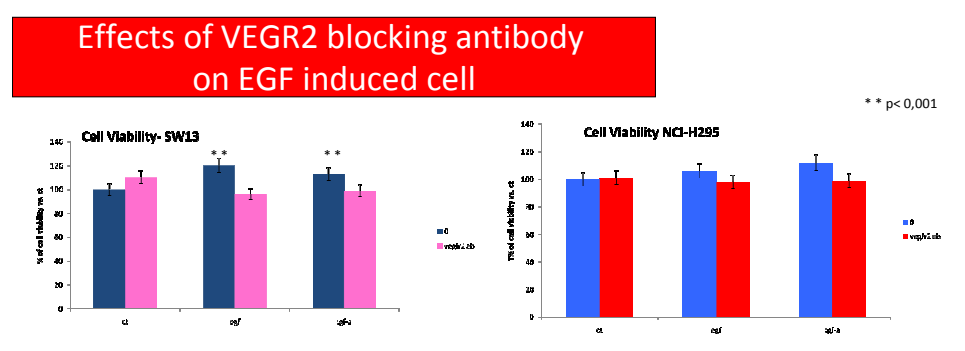

VEGF receptor (VEGFR) blocking antibody significantly reduced EGF effects on SW13 cells proliferation, while it had negligible effects on $\mathrm{NCl}-\mathrm{H} 295$ cells

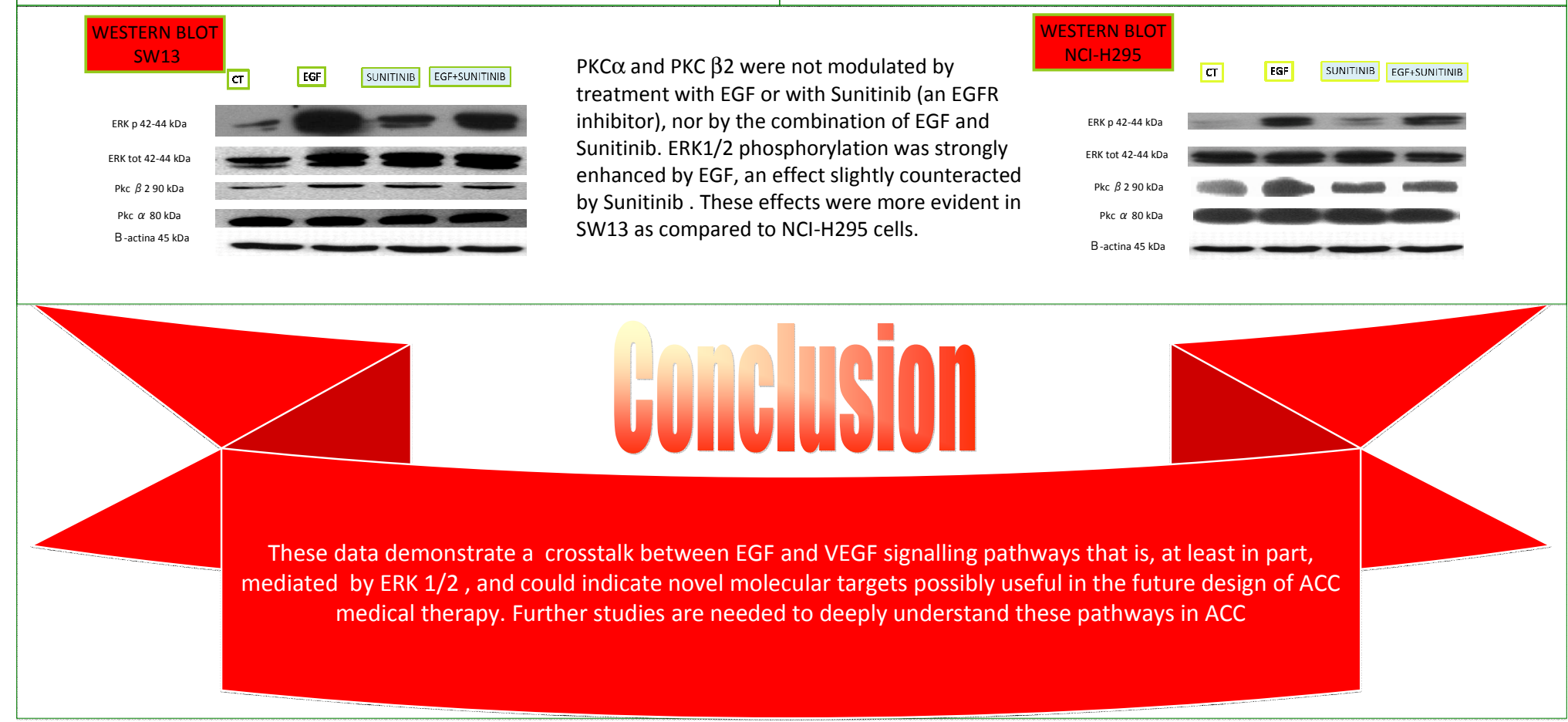

